\title{
System of Mathematics Teachers' Beliefs about Effective Teaching/Learning and Practice as a Complex Adaptive System
}

\author{
Aḷesja Šapkova \\ Faculty of Management and Education, Daugavpils University \\ LV5400, Latvia, Daugavpils, Parādes iela 1
}

Tel: 37-12-610-3165 E-mail: alesja.shapkova@gmail.com

Received: February 15, 2014 Accepted: July 16, 2014 Published: August 1, 2014

doi:10.5296/jse.v4i3.5119 URL: http://dx.doi.org/10.5296/jse.v4i3.5119

\begin{abstract}
The outcomes of the research on teachers' beliefs and their relatedness to their work routine are often contradictory, hard to systematize and predict. This may be evidence that research on teachers' beliefs need a change in research paradigm: it should regard various approaches, in other words, research should be carried out in the Holistic paradigm framework. As a field inquiry concerned with the holistic exploration of phenomena and events, systems theory pertains to both epistemological and ontological situations. The present article suggests to emphasize in inquiries on mathematics teachers' beliefs the bond of teachers' beliefs with their practice and analyze the system of mathematics teachers' beliefs and practice (SMTBP) from the position of Complex Adaptive System (CAS). The aim of the article is to show that the basic features of CAS are present in SMTBP as well and that there exist some features of CAS that have not been sufficiently regarded in previous research on teachers' beliefs but that could be used to characterize the change of teachers' beliefs and the processes of practical implementation of teachers' beliefs in their work. The article is focused on the external factors that may affect these processes, and the principle of Bronfenbrenner ecological system theory has been used for systematizing them. Application of CAS Theory for the studies of SMTBP will provide a unified approach to interpreting the outcomes concerning teachers' beliefs that, in turn, will make it possible to account for a large number of revelations that were impossible to account for within the framework of non-holistic paradigms.
\end{abstract}

Keywords: Complex Adaptive Systems Theory, Mathematics teachers' beliefs and practice, Bronfenbrenner's ecological system theory 


\section{Introduction}

In the twentieth century several disciplines of the contemporary science have acquired an extremely large number of observations that could not be accounted for adequately within the framework of monistic materialist world vision or, in other words, in the context of Newtonian-Cartesian paradigm (Capra, 1975). The breach of this paradigm, in order to understand the point of "anomalous phenomenon", was facilitated by the needs of various branches of astrophysics, quantum physics, chemistry, biology, anthropology, and psychology. Thus the previously dominant way of thinking both in science and society is being replaced by the holistic thinking (Laszlo, 1996).

Change of paradigms becomes the cause of essential changes in the paradigm of education research. The diversity of education research paradigms (the Behaviorist, the Cognitive-Developmental, the Humanistic) set an inevitable problem for researchers - what paradigm and corresponding strategies and methods of research, etc. to choose for inquiries? (Popp, 1975)

The author of the present article holds that in education research one needs the integration of specific/anomalous research discoveries or, in other words, education should be studied within the holistic paradigm (Dewey, 1933), as the latter does not contradict any other paradigm. It rather accepts the discoveries produced within other paradigms as a part of the whole that includes more. Hence, the research discoveries related to other education paradigms are regarded as a part of a large, more unified system of totality (Zigler, 1978).

Recent studies in empirical sciences prepared the base for the new overall empirical theory that is related to holistic, integrated study of phenomena and events: system theory. If the specific objects of various sciences are united within dynamic systems, any phenomenon may be determined by using a set of systems. Mutual relatedness among systems is not clear as their existence is determined in different disciplines that exist at different organization levels in nature (general systems theory). Systems are interrelated by "horizontal" interactions within the level of the system itself as well as "vertical" interactions within systems of various levels. The interdisciplinary researcher, philosopher, the world famous scientist Ervin Laszlo is considered to be the author of systems theory.

The present article is focused on mathematics teachers' beliefs and practice. Belief is individual, more seldom stable subjective knowledge that includes person's feelings or cares (Pehkonen, 1994). The term "teachers' beliefs" is usually used to describe teachers' beliefs in education (Borg, 2001). Teachers' beliefs comprise both the professional knowledge of teachers and their willingness to apply this professional knowledge in their routine practice.

Out of a whole range of teachers' beliefs, the present article analyzes only teachers' beliefs about effective teaching and learning (BETL). Teachers' BETL comprise encompassing beliefs held by teachers both about the impact of teaching and the way learners learn (McMullen et al., 2006). As the subject taught also affects teachers' beliefs (Lerman, 1990), the present research is concerned with mathematics teachers' beliefs about effective 
mathematics teaching and learning (BEMTL) (Wood et al., 1991; Ernest, 1989; Papert, 1980).

Notwithstanding the long time of research, mathematics teachers' beliefs (BETL and BEMTL) are still understudied (Mansour, 2009). According to the author of the present article, it is related to the situation that in studies of teachers' beliefs a large number of outcomes is acquired that cannot be accounted for within the framework of non-holistic paradigms. Therefore, investigating the system of teachers' beliefs and practice, the author suggests focusing on the relation between teachers' beliefs and their practice and further regard a complex educational and socio-psychological system: System of Mathematics Teachers' Beliefs (BETL and BEMTL) and Practice (SMTBP), that, in turn, could be regarded as a complex adaptive system (CAS) - a dynamic network having several elements the functioning whereof is coordinated within a single system and that are in constant interaction among one another and with the environment (Holland, 1992; 1995).

CAS may be characterized in short by the following: a) a large number of similar but at the same time independent elements; b) constant movement of agents and interaction with other agents/elements; c) adaptivity; in other words, the system adapting to the new situation in order to survive; d) self-organization; this means that the order within the system is formed incidentally; e) local rules assumed by each agent; and f) progress of complexity; i.e. in the course of time the system becomes more and more complicated (Garnet, 1997). It must be noted that other scholars (Fryer, 2009; Cleveland, 1994) single out also other features of CAS system, e.g. butterfly effect, compatibility, variety and many others.

At present many education scholars are focusing on the complex character of education and use the theory of complication as a useful research paradigm, in order to account for the changes within the framework of complex social systems (e.g. Davis \& Sumara, 2006; Radford, 2006). However, it must be noted that the present research is one of the first to postulate that SMTBP as CAS and that dynamic non-linear changes that take place within this system may be effectively interpreted by using the model of CAS theory. CAS theory is a theory about the emergence of order I systems that have recently been very chaotic and disorderly. In what way and for what reason such an order emerges in systems remains a mystery, yet the understanding of the impact of systems on the functioning of various organizations/structures may considerably improve the action of human (Mcelroy, 2000).

Hence, the aim of the present article is to describe SMTBP so that to bring out CAS features in it and, on the other hand, to show that there exist some CAS features that were disregarded in prior studies on teachers' beliefs and their practice but that may be used to interpret the outcomes of inquiries about teachers' beliefs/practice. CAS basic features present in SMTBP will be emphasized further in the present article.

In the present article the processes of teachers' change of beliefs and realization beliefs in practice will be accounted for by using CAS theory. Special attention will be paid to the external factors affecting the change of teachers' beliefs and realization beliefs in practice. Bronfenbrenner's ecological systems theory principle will be used for systematizing external factors and justifying the structure of these factors. 


\section{Mathematics teachers' SMTBP}

Interactive SMTBP cannot be set in advance and controlled. It is a nonlinear complex system that is constantly adapted to the surrounding environment. Each SMTBP sub-system, BETL and BEMTL, has a large number of similar but at the same time independent elements. For instance, BETL system elements can be mathematics teachers' beliefs about using didactic games in mathematics lessons, learners' group-work, project oriented teaching, independent discoveries of learners, etc. BEMTL elements, in turn, can entail beliefs about using the language of mathematics in classes, emphasis on logical thinking, mathematic calculations, etc.

Both SMTBP sub-systems, BETL and BEMTL, have a nested structure: each of the systems is located within another larger system (e.g. that of teachers' beliefs) and they contain other, smaller systems of beliefs. For instance, traditional/formal/constructivist BEMTL systems (Dionne, 1984) are sub-systems of BEMTL system, traditional/constructivist BETL systems (OECD, 2009; Staub \& Stern, 2002) are sub-systems of BETL system, etc.), that, in turn, may be divided in even smaller sub-groups (e.g. constructivist BETL system may be divided into the sub-groups like Independent discoveries, Connection with real life, Self-regulated teaching, etc.). See Appendix 1.

\section{Change of teachers' beliefs}

SMTBP exists within the professional action system of each particular mathematics teacher; it is affected by various factors (e.g. the attitude of the school staff, administration, national education policies, economic conditions, etc.). Further on we will call the whole of factors affecting SMTBP teacher's environment. Hence, if the school environment changes (e.g. the school staff and/or administration and/or education policy, etc.) then SMTBP must change, too, in order to provide the best congruence with the environment (adaptivity). But, as SMTBP makes a part of teacher's environment, changes there causes change in its environment (feedback) that, in turn, conditions changes in SMTBP and so on. There is a constant process of system-environment change (constant motion).

The process of change of teachers' beliefs is schematically reflected in Appendix 2 and all processes depicted there will be explained in this part.

Small changes in the initial SMTBP environment conditions may cause a significant effect as the process of system-environment change, owing to feedbacks, may happen several times ( $\underline{a}$ butterfly effect). Interacting with its environment, all environmental problems and requirements, teachers become aware and assess their beliefs even more than others (Thompson, 1992). The changes in SMTBP happen as follows: 1) new, unstable elements appear (possible new beliefs) or the status of the previous, "old" system elements changes (the correctness of some belief is doubted). These elements are beliefs that may change but they will change only if their correctness will be proved in practice by each particular teacher (see Appendix 2). So, Guskey (Guskey, 1986) points out that teachers' beliefs and attitudes may undergo essential change only when they see changes in the process and outcomes of learners' learning. 
SMTBP elements must be united around a common idea: all system elements must be aimed at more efficient developing of learners' mathematical abilities and/or at learners being able to achieve the highest results in mathematics (regularities). As a result of the new SMTBP element impact, new ideas appear for teachers' practice. This results in the development of learners' abilities in mathematics and/or learners' achievements in mathematics. Depending on whether the outcome of the changing SMTBP impact proves satisfactory for the teacher of mathematics or not, these beliefs (owing to the impact whereof the outcome has been achieved) are either consolidated or rejected, or new beliefs are taken, in other words, beliefs are changed (self-organization). Sometimes this process is cyclical, when some beliefs are tested in practice several times. This accounts for the fact that the change of teachers' beliefs is a slow process, and there are no means yet to make it faster; also just a small number of teachers actually do change their beliefs (Handal, 2003b). In addition, social and cognitive psychology research shows (Dweck, 2008) that any adult person's beliefs change slowly: the more important (central) the person's beliefs are, the more tests and proofs in practice are needed.

The process of change of beliefs cannot be planned or guided but it is related to constant reorganization, in order to best adapt to the environment as well as achieve the best results, e.g. learners' higher achievements. The way beliefs are interrelated and affect one another, is critically important for the survival of the system, therefore these relations and impacts form a system and condition spreading of feedback. Relations among the elements are more important than the system elements as such (connectivity).

Thus in the course of time SMTBP becomes bigger and more complex. As a result of the process of change of beliefs, the system diversity may grow larger. The higher the degree of system diversity, the stronger it is. CAS makes use of contradictions to acquire new opportunities for developing with its environment. Thus, the more (at first sight seemingly contradictory - traditional, constructivist, formal) beliefs about teaching and learning (mathematics) the particular mathematics teacher holds, the more opportunities there exist for this teacher to get adapted to new conditions.

However, it must be noted that accepting new beliefs or rejecting them depends on each personality (each teacher) and this is a voluntary process.

Depending on the teacher's personality, the change of the teacher's beliefs may happen deductively or inductively (author). Deductive change of teacher's beliefs is a process of accepting/rejecting beliefs that happens as follows: there exist some external factors/macro-beliefs (e.g. philosophy of mathematics, theoretical base of education, education reforms, new programs, standards, administration/parent requirements) that affect whether the teacher accepts or rejects the new beliefs (BETL and BEMTL). If the new accepted beliefs of the teacher will not be approved of in the everyday practice, there is a probability that as soon as the influence of the external factors decreases, the influence of the respective beliefs on the everyday practice will decrease, too. Due to the fact that a teacher is often unaware of the impact of external factors/macro-beliefs and it may be chaotic, contradictory, or not regular, and the accepted/rejected beliefs are not adapted to the needs of 
the particular teacher, the deductive process of accepting/rejecting beliefs may be slow, long, and often ineffective.

Inductive change of teacher's beliefs is individual and independent construction of a particular teacher's beliefs. Unlike the deductive change of teacher's beliefs, the inductive change is characteristic of teachers with an active position of life. We selected constructivism as the methodological base of constructing beliefs, as it is based on an active involvement of the human in creating and constructing knowledge. As was mentioned above, beliefs contain both knowledge and emotions. Therefore it is possible to speak not only about the construction of knowledge but also that of beliefs.

Proceeding from the constructivist perspective in knowledge construction process (Brooks \& Brooks, 1993; Bybee, 1997; Eisenkraft, 2003), inductive change of teacher's beliefs may be depicted as a cycle: 1) acquiring and understanding knowledge/information that is the basis of the particular belief (also under the impact of external factors); 2) approbation of this knowledge in the teachers' practice or acquisition of positive or negative teaching experience; 3) summarizing of the acquired knowledge, extending the borders of beliefs/ adapting beliefs if they are shared by other teachers as well; 4) critical assessment of the newly acquired experience, searching for possible alternative solutions of the problem, and then returning to point 1 again. As in the inductive process of change of a teacher's beliefs there is intentional adapting/adjusting of beliefs to the individual teacher's desires, needs, and system of beliefs, the inductive process of the change of beliefs is a long-term and sustainable one.

Teachers' beliefs and also the everyday practice of teachers is developed for each teacher on the basis not only of unique personality factors of the teacher but also the context and time factors (Drang, 2011). Therefore we will further regard those external factors that can actively interact with SMTBP. Let us note that these factors (both socially and biologically determined teacher's personality traits) also may actively interact with SMTBP, yet they are not regarded in the present article.

\section{Teachers' external environment: ecological system theory principle}

To systematize the external factors that may affect SMTBP, we will use Bronfenbrenner's ecological system principle. Bronfenbrenner elaborated the ecological system theory to define and understand human development in the context of a system of such relations that make up an environment for a person. According to Bronfenbrenner's initial theory (1989), environment consists of four system layers that interact in a complex way and may both affect the person's development and get changed themselves under the influence of a person. Each of the four system layers - microsystem, mesosystem, ecosystem, and macrosystem, will be described in detail below in line with ecological system theory, and SMTBP external environment functioning model is depicted in Appendix 3 (different system layers are depicted in different colours).

Microsystem is a model/structure of a person's (in the context of the given research teacher's) actions, roles, and mutual relations that develops under specific conditions, with specific physical and material features, and it entails also other persons with their 
temperament, personality, and belief system traits (Bronfenbrenner, 1995). In other words, this layer is a complex of such models/structures wherewith a person (teacher) has a direct contact, and they (a person (teacher) and the structure) mutually affect each other. Further description refers to elements in Appendix 3 in light blue colour.

SMTBP has three microsystem sub-systems: (1) childhood/school, (2) professional partnership, (3) learning partnership sub-systems.

SMTBP childhood/school sub-system is a complex of structures/models wherewith a teacher had a direct contact in his/her childhood and/or learning that, in turn, affected/still affect/hypothetically could have affected SMTBP: 1) parents and/or family members; 2) friends, classmates, peers; 3) (mathematics) teachers, university professors, educators at school, higher education, or "significant others".

SMTBP professional partnership sub-system is a complex of structures/models wherewith a teacher had/has a direct contact within his/her professional action and further education: 4) colleagues; 5) administration; 6) subject methodologists.

However, one ought to note that SMTBP to a similar extent affects also 7) teacher's learners and 8) learners' parents who may be united within SMTBP learning partnership sub-system.

It cannot be stated for sure which of these sub-systems is stronger and at what moment, as they are in a constant interaction. However, one may set a hypothesis that teacher's recently formed beliefs are more affected by two latter sub-systems, while the earlier formed beliefs that a teacher is often even unaware of have been more affected by the childhood/school sub-system.

The previously described SMTBP microsystem is in no contradiction to research that states that teachers' microsystem includes their partnerships with learners, parents, colleagues, administration, and family (Drang, 2011).

Mesosystem includes mutual relations among the microsystem sub-systems, as well as among the sub-system structures (Bronfenbrenner, 1995). In Appendix 3 these relations are marked by blue arrows.

An example of SMTBP childhood/school sub-system mesosytem appears in the interaction and dynamics of its three structures/elements: 1) friends/peers, 2) child's parents, and 3) child's (mathematics) teacher. In previous research about teachers' beliefs the significance of their own teachers is emphasized. Handal (2003) writes that in the process of learning learners acquire not only content based knowledge but also strategies of learning. By the moment when the would-be teacher enters university, his/her beliefs about how to teach and learn have become deeply rooted in the individual under the influence of his/her own teachers' practice and very often these beliefs are of a rather traditional character (Brown \& Rose, 1995; Day, 1996).

The example of SMTBP professional partnership sub-system mesosystem appears in the interaction and dynamics of its three structures/elements: 1) colleagues, 2) administration, 3) methodologists. The interaction and dynamics of school administration, colleagues and 
methodologists, in other words, school climate indicators are often a cause for contradictions for SMTBP (Erickson, 1993; Mansour, 2009).

Teacher having at his/her disposal great freedom of choosing the most adequate approach to teaching makes it easier for teacher to coordinate his/her views and teaching practice. This conclusion matches McNeil's research findings (McNeil, 1986) - attempts to improve teaching and learning by means of strict control that Cornbleth (Cornbleth, 2001) calls the climate of "law and order", leads to traditional teaching and undermines learners' meaningful learning and critical thinking development. This means that administration ought to provide teachers bigger support and more freedom, so that the latter could create such a learning environment that facilitates an ideal process of learning. In the case of the formal system of education, teachers are rather products of school environment and not its creators. School environment (colleagues, administration, methodologists) could be perceived as that imposed on teachers. Thus, school environment may be regarded as a factor affecting the system of teachers' beliefs and their practice (Pipere \& Lepik, 2013).

SMTBP learning partnership sub-system mesosystem can be exemplified by the interaction of learners and their parents and its further impact on a teacher. Parents' expectations and hopes regarding their children's success in the academic education programme and outside it often create dynamics that both directly and indirectly affects the atmosphere and climate at school (Johnson, 2008), that, in turn, affects SMTBP. Ungrounded expectations may create such a dynamics between parents and their children that is characterized by tension and fear. Such a dynamics affects school in various direct and indirect ways, including, e.g. learners' conduct in class that follows from such expectations of parents; pressure on parents' part affects school staff as they wish to secure higher achievement of their children or school staff may try to safeguard learners from this kind of pressure form parents, etc.

Ecosystem represents the big social system that includes events, unpredicted conditions, decisions, and politics, upon which a person (in this context - a teacher) has no influence. Ecosystem may hold, e.g. a bond between the local education council and a teacher, or between the learners' home life and a teacher (Drang, 2011). An ecosystem, thus forms a direct or indirect one-way impact on a person (teacher). SMTBP ecosystem may contain such structures as, e.g. local policies, local economy as well as local social conditions (see Appendix 3 elements in green). Erickson (Erickson, 1993) in fact concluded that teachers' beliefs have a big impact on their everyday practice. However, the obstacles that do not let implement their beliefs fully include such sub-factors of the local policy and economy as lack of time for preparing lessons, the number of learners in class, access to technologies, material and financial support, teachers' growth opportunities, etc.

Macrosystem is a "social blueprint" of a given culture and subculture, or in a wide social context the former of the system of the main values, beliefs, and views, lifestyle, opportunities and resources (Johnson, 2008). This system usually makes a one-way impact on not only a person (teacher) but also the micro-, meso-, and ecosystem. Teacher's macrosystem holds not only the cultural, political, social, and economic climate of the local (e.g. state) society but also that of the global (e.g. Europe) society (Drang, 2011). Hence, 
SMTBP macrosystem may have such macrosystem factors as the local and global culture (e.g. cultural beliefs about child's conduct and teacher's role), expectations and hopes of the local and global culture, a wide context of historical events as well as macrobeliefs (e.g. about mathematics, the theoretical basis of education as well as the culture of education) (see in Appendix 3 the elements in violate).

The numerous external factors of teacher environment may have an active interaction with SMTBP and become a cause of the realization/non-realization of teacher's beliefs in practice. However, even if there are no actual impediments to realization teachers' beliefs in practice, the implementation of their beliefs in teachers' routine practice may not be stable. To realize the point of the given phenomenon, the next part regards the process of realization teachers' beliefs in practice within CAS theory.

\section{Realization teachers' beliefs in practice}

The issue of the way teachers' beliefs (BETL and BEMTL) affect or are related to teachers' practice is a very active sphere of investigation (Philipp, 2007). Relation between teachers' beliefs and practice is complicated because it depends on many social norms, each of which has its own limitations: from learners', parents', administration values, hopes, and beliefs (Thompson, 1984; Cooney, 1985; Brown, 1986). However, notwithstanding the fact that the system of teacher's beliefs (BETL and BEMTL) may be complex and manifold, the rules regulating the functioning of the system of beliefs are quite simple: beliefs acquired once must be implemented in class practice (Handal, 2003b) (simple rules). Savasci-Acikalin (Savasci-Acikalin, 2009) points out that beliefs refer to assumptions, trusting ideology and do not require being absolutely true, but knowledge refers to judgments about facts and understanding that they must meet the "conditions of truth". Hence, if teachers believe that some learning strategy is well justified and if this strategy as well is based on beliefs that are similar to their own ones, teachers will search for a way to put this strategy to practice. If a teacher considers this to be a waste of time, s/he will look for justification of this opinion (Yero, 2002).

Hence, teachers' everyday practice is more affected by their beliefs than their knowledge. Therefore in the present research, as mentioned before mathematics teachers' system of beliefs (BETL and BEMTL) was not separated from their practice and was regarded as a unified system of mathematics teachers' beliefs (BETL and BEMTL) and practice (SMTBP).

However, these simple rules are implemented if 1) there is no contradiction between the systems of teachers' beliefs and practice and teachers' (external) environment factors. Teachers' external environment factors may be a major obstacle to realization teachers' beliefs in practice (e.g. school administration does not support teachers' beliefs on teaching and learning mathematics); 2) the resources are sufficient (e.g. insufficient technical equipment of a classroom, lack of time, lack of knowledge and skills hold teachers physically back from implementing their beliefs in classroom). Otherwise teachers may take new beliefs on good practice of teaching mathematics without changes in their actual practice (Desforges \& Cockburn, 1987). 
Quinn and Wilson (Quinn \& Wilson, 1997) set a hypothesis that the reasons for the incongruence of teachers' beliefs to their practice may lie in the impediments to making changes in teachers' practice. In their study they came to a conclusion that, despite the fact that teachers have a positive attitude to using writing in teaching mathematics, teachers do not implement this belief in their routine work. The reason for this may be lack of time. Other study (Van Zoest et al.,1994) reveals that teachers could not transfer their socio-constructivist beliefs BEMTL to teaching practice due to the lack of teaching skills. Erickson (Erickson, 1993) points out that teachers' beliefs have a great impact on their everyday practice. However, the impediments that do not let fully implement their beliefs include such sub-factors of local policies and economy as lack of time for preparing lessons, the number of learners in class, access to technologies, materials, financing, opportunities of teacher's growth, etc.

This assumption may be supported by the social cognitive theory, too. According to Bandura's triadic reciprocal causation model (Bandura, 2001) that is the base of the social cognitive theory, human conduct (for teachers - their practice), human cognitive abilities and other personal factors (e.g. the system of teachers' beliefs (BETL and BEMTL)) and environment (teachers' external environment) - these factors (determinants) affect one another in mutual interaction (Bandura, 1989). People's beliefs, feelings, and thoughts affect their conduct (Bandura, 1986; Bower, 1975; Neisser, 1976). Conduct changes the environment conditions and, vice versa, gets formed itself under certain conditions of environment (Bandura, 1989). The correlation of teachers' beliefs, preferences, and practice is not directly proportional (Liljedahl, 2009), but, as revealed by Beswick (Beswick, 2005), beliefs and practice develop together and affect one another, as they are dialectically interrelated.

However, even if there are no actual impediments to realization teachers' beliefs in practice, even then the implementations of teachers' beliefs in their practice is not always stable. Let us consider a concrete example of unsustainable use of didactical games in mathematics lessons, that often occurs in the actual practice of teachers (see Appendix 4).

Teacher decides to test in practice the belief that using didactical games in mathematics lessons develops learners' mathematical abilities and/or raise learners' achievement in mathematics. If the test (or several tests) in practice yields a positive result, the teacher will change/reject/approve of a belief of his/her concerning using didactical games in his/her practice (belief origin) (see Appendix 2) and will start actively use didactical games in everyday practice (if there are no actual impediments) in various topics, several classes, will improve the rules, kinds, forms of using didactical games, in other words, the newly accepted belief will become actively "exploited" and improved in practice (see Appendix 4).

However, the process of active exploitation and improvement of a belief cannot be endless and finally the process of stabilization will ensue. In fact, the whole process of learning cannot be drawn only from didactical games, in the end a teacher will choose a more adequate form and frequency of using this work form/method in lesson, depending on one's preferences and the class context. 
Here ensues the most dangerous instance as often after stabilization the system of beliefs and practices may become stable and unchanging, in other words, a non-adaptive system. The system of teachers' beliefs and practices will ignore the impact of new factors of teachers' external environment, but these new factors will certainly appear and destabilize it (destabilization process) (see Appendix 4).

\section{Conclusions}

The notion "system" occupies the central place in contemporary science, society, and life as the necessity for the "system approach", "system thinking" is emphasized. To understand the whole, it is important in research on (mathematics) teachers' beliefs to study not only separate elements, mathematics teachers' beliefs on effective (mathematics) teaching and learning, but also the mutual relation of these elements as well as emphasize the close bond between teachers' beliefs and their practice and study the unified system of mathematics teachers' beliefs and practice.

It has been revealed in the present article that the system of mathematics teachers' beliefs and practice possesses such basic qualities of Complex adaptive systems as a large number of elements, adaptivity, constant motion, butterfly effect, self-organizing, connectivity, diversity, thus it was theoretically grounded that the system of teachers' beliefs and practice is a Complex adaptive system. Besides, the process of change of teachers' beliefs and belief implementation have been described using CAS theory, developing the models of the above mentioned processes in line with CAS theory (see Appendix 2-3). These models like the deductive and inductive mechanisms of teachers' belief change may be used to interpret the outcomes of the research on teachers' beliefs.

External factors that may affect the system of mathematics teachers' beliefs and practice were collected and systematized by means of Bronfenbrenner's ecological system theory principle. Thus, four layers of teachers' environment were described in detail: microsystem, mesosystem, ecosystem, and macrosystem. A hypothesis was set that incongruences of teachers' beliefs and their practice testify to either contradictions between teachers' belief and practice systems and teachers' (external) environment factors, or teachers lack resources to put their beliefs to practice. Also if there are no actual impediments to implementing teachers' beliefs in practice, practicing their beliefs in teachers' everyday routine may not be stable.

Though the theoretical analysis presented above is related to the sphere of mathematics education, this theory may be used not only to analyze mathematics teachers' beliefs and practice but also those of other subject teachers. Using the principle of system theory in studying teachers' beliefs will make it possible to interpret the results within the holistic paradigm and summarize a large number of discoveries that could not be accounted for previously within non-holistic paradigms.

\section{References}

Bandura, A. (1986). Social foundations of thought and action: A social cognitive theory. Englewood Cliffs, NJ: Prentice-Hall, Inc. 
Bandura, A. (1989). Self-regulation of motivation and action through internal standards and goal systems. In L. A. Pervin (Ed.), Goal concepts in personality and social psychology (pp. 19-85). Hillsdale, NJ: Lawrence Erlbaum Associates.

Bandura, A. (2001). Social Cognitive Theory: An Agentic Perspective, Annual. Reviews of Psychology, 52, 1-26. http://dx.doi.org/10.1111/1467-839X.00024

Beswick, K. (2005). It depends on the students: Influencing teacher beliefs about the ends and means of numeracy teaching. In P. Clarkson, A. Downton, D. Gronn, M. Horne, A. McDonough, R. Pierce, \& A. Roche (Eds.), Building connections: Research, theory and practice (Proceedings of the 28th annual conference of the Mathematics Education Research Group of Australasia, Vol. 1, pp. 137-144). Sydney: MERGA.

Borg, M. (2001). Teachers' beliefs. ELT Journal, 55 (2), 186-188.

Bower, G. H. (1975). Cognitive psychology: An introduction. In W. K. Estes (Ed.), Handbook of learning and cognitive processes (Vol. 1). Hillsdale, N. J.: Lawrence Erlbaum Associates.

Bronfenbrenner, U. (1989). Ecological systems theory. Annals of child development, 6, 187-249.

Bronfenbrenner, U. (1995). Developmental ecology through space and time: A future perspective. In P. Moen, \& G. H. Elder, Jr. (Eds.), Examining lives in context: Perspectives on the ecology of human development (pp. 619-647). Washington, DC: American Psychological Association. http://dx.doi.org/10.1037/10176-018

Brooks, J. G., \& Brooks, M. G. (1993). In search of understanding: The case for constructivist classrooms. Alexandria, VA: Association of Supervision and Curriculum Development.

Brown, C. A. (1986). A Study of the socialization to teaching of a beginning mathematics teacher. Doctoral dissertation, University of Georgia. Dissertation Abstracts.

Brown, D. F., \& Rose, T. D. (1995). Self-reported classroom impact of teachers' theories about learning and obstacles to implementation. Action in Teacher Education, 17(1), 20-29.

Bybee, R.W. (1997). Achieving scientific literacy. Portsmouth, NH: Heinemann.

Capra, F. (1975). The Tao of Physics. Berkeley: Shambhala.

Cleveland, J. (1994). Complexity Theory: Basic Concepts and Application to Systems Thinking, Innovation Network for Communities, Retrieved from 199http://www.slideshare.net/johncleveland/complexity-theory-basic-concepts.

Cooney, T. J. (1985). A beginning teacher's view of problem solving. Journal for Research in Mathematics Education, 16 (5), 324-336. http://dx.doi.org/10.2307/749355

Cornbleth, C. (2001). Climates of constraint/restraint of teachers and teaching. In W. B. Stanley (Ed.), Critical issues in social studies research for the 21st century. Greenwich, CT: Information Age Publishing.

Davis, B., \& Sumara, D. (2006). Complexity and education: Inquiries into learning, teaching, 
and research. Mahway, NJ: Lawrence Erlbaum Associates.

Day, R. (1996). Case studies of preservice secondary mathematics teachers' beliefs: Emerging and evolving themes. Mathematics Education Research Journal, 8(1), 5-22.

Desforges, C., \& Cockburn, A. (1987). Understanding the Mathematics Teacher. Lewes: Falmer Press.

Dewey, J. (1933). How We Think: A Restatement of the Relation of Reflective Thinking to the Educative Process. Boston: D.C. Heath and Co.

Dionne, J. (1984). The perception of mathematics among elementary school teachers. In J. Moser (Ed.), Proceedings of the 6th Annual Meeting of the North American Chapter of the International Group for the Psychology of Mathematics Education (pp. 223-228). Madison, WI: University of Wisconsin.

Drang, D.M. (2011). Peschool teachers' beliefs, knowledge, and practicee related to classroom management. Retrieved from http://drum.lib.umd.edu/bitstream/1903/12370/1/Drang_umd_0117E_12828.pdf

Dweck, C.S. (2008). Can personality be changed? The role of beliefs in personality and change. Current Directions in Psychological Science, 17, 391-394. http://dx.doi.org/10.1111/j.1467-8721.2008.00612.x

Eisenkraft, A. (2003). Expanding the 5E model. Science Teacher, 70(6), 56-59.

Erickson, O.K. (1993). Middle school mathematics teachers' view of mathematics and mathematics education, their planning and classroom instruction, and student beliefs and achievement. Proceedings of the Annual Conference of the American Educational Research Association. Atlanta, GA.

Ernest, P. (1989). The knowledge, beliefs and attitudes of the mathematics teacher: A model. Journal of Education for Teaching, 15(1), 13-33. http://dx.doi.org/10.1080/0260747890150102

Fryer, P. (2009). A brief Description of Complex Adaptive Systems and Adaptive Theory. Retrieved from www.trojanmice.com/articles/complexadaptivesystems.htm.

Garnet, P.W. (1997). Chaos Theory Tamed. Washington: Joseph Henry press.

Guskey, T.R. (1986). Staff development and the process of teacher change. Educational Researcher, 15(5), 5-12. http://dx.doi.org/10.3102/0013189X015005005

Handal, B. (2003a). Constructivist and behaviourist teachers. International Online Journal of Mathematics and Science Education. Retrieved from http://www.upd.edu.ph/ ismed/online/articles/profiling/abstract.htm

Handal, B. (2003b). Teachers' mathematical beliefs: A review. The Mathematics Educator, 13(2), 47-57.

Holland, J. H. (1992). Adaptation in Natural and Artificial Systems. MIT Press. 
Holland, J. H. (1995). Hidden Order: How Adaptation Builds Complexity. Helix Books.

Johnson, E.S. (2008). Ecological Systems and Complexity Theory: Toward an Alternative Model of Accountability in Education. Complicity: An International Journal of Complexity and Education, 5(1), 1- 10.

Laszlo, A. (1996). The Systems View of the World: A Holistic Vision for Our Time. Hampton Press.

Liljedahl, P. (2009). Teachers' insights into the relationship between beliefs and practice. In J. Maa $\beta$, \& W. Schlöglmann (Eds.), Beliefs and Attitudes in Mathematics Education: New Research Results, (pp. 33-43). Rotterdam, The Neatherlands: Sense Publishers.

Mansour, N. (2009). Science teachers beliefs and practices: Issues, implications and research agenda. International Journal of Environmental \& Science Education, 4(1), 25-48.

Mcelroy, M.W. (2000). Integrating complexity theory, knowledge management and organizational learning. Journal of Knowledge Management, 4(3), 195-203. http://dx.doi.org/10.1108/13673270010377652

McMullen, M., Elicker, J., Goetze, G., Huang, H.H., Lee, S.M., Mathers, C., Wen, X., \&Yang, H.Y. (2006). Using collaborative assessment to examine the relationship between self reported beliefs and the documentable practices of preschool teachers. Early Childhood Education Journal, 34(1), 81-91. http://dx.doi.org/10.1007/s10643-006-0081-3

McNeil, L.M. (1986). Contradictions of control: School structure and school knowledge. New York \& London: Routledge \& Kegan Paul.

Neisser, U. (1976). Cognition and Reality: Principles and Implications of Cognitive Psychology. WH Freeman.

OECD. (2009). Creating Effective Teaching and Learning Environments: First Results from TALIS. Paris: OECD Publishing.

Papert, S. (1980). Mindstorms: Children, Computers and Powerful Ideas. New York: Basic Books.

Pehkonen, E. (1994). Teachers' and pupils' beliefs in focus - consequence of constructivism. In M. Ahtee, \& E. Pehkonen (Eds.), Constructivist Viewpoints for School Teaching and Learning in Mathematics and Science (pp. 27-33). Helsinki: University of Helsinki. Department of Teacher Education.

Philipp, R. A. (2007). Mathematics teachers' beliefs and affect. In F. K. Lester (Ed.), Second Handbook of Research on Mathematics Teaching and Learning (pp.257-315). Charlote, NC: National Council of Teachers of Mathematics.

Pipere, A., \& Lepik M. (2013). Job satisfaction, beliefs and instructional practice: the case of Latvian and Estonian mathematics teachers. Electronic Journal of Research in Educational Psychology, 11(1), 167-192. 


\section{Macrothink}

Journal of Studies in Education

ISSN 2162-6952

2014, Vol. 4, No. 3

Popp, J. A. (1975). Paradigms in Educational inquiry. Educational Theory, 25, 28-39. http://dx.doi.org/10.1111/j.1741-5446.1975.tb00664.x

Quinn, R. J., \& Wilson, M. M. (1997). Writing in the mathematics classroom: Teacher beliefs and practices. The Clearing House, 71(1), 14-21. http://dx.doi.org/10.1080/00098659709599316

Radford, M. (2006). Researching classrooms: Complexity and chaos. British Educational Research Journal, 32(2), 177-190. http://dx.doi.org/10.1080/01411920600568950

Savasci-Acikalin, F. (2009). Teacher beliefs and practice in science education. Asia-Pacific Form on Science Learning and Teaching, 10(1), 1-14.

Staub, F. C., \& Stern, E. (2002). The nature of teachers' pedagogical content beliefs matters for students' achievement gains: Quasi-experimental evidence from elementary mathematics. Journal of Educational Psychology, 94(2), 344-355.

Thompson, A. G. (1984). The relationship of teachers' conceptions of mathematics and mathematics teaching to instructional practice. Educational Studies in Mathematics, 15, 105-127.

Thompson, A. G. (1992). Teachers' beliefs and conceptions: A synthesis of the research. In D. A. Grouws (Ed.), Handbook of research on mathematics teaching and learning: A project of the National Council of Teachers of Mathematics (pp. 147-164). New York, NY: Macmillan.

Van Zoest, L., Jones, G. A., \& Thornton, C. A. (1994). Beliefs about mathematics teaching held by pre-service teachers involved in a first grade mentorship program. Mathematics Education Research Journal, 6(1), 37-55. http://dx.doi.org/10.1007/BF03217261

Wood, T., Cobb, P., \& Yackel, E. (1991). A Constructivist Approach to Second Grade Mathematics. In E. von Glasersfeld (Ed.), Radical Constructivism in Mathematics Education (pp. 157-176). DordrechtKluwer.

Yero, J. L. (2002). Teaching in mind: How teacher thinking shapes education. Hamilton, MT: MindFlight Publishing.

Zigler, R. L. (1978). The Holistic Paradigm in Educational Theory. Educational Theory, 28(4), 318-326. 


\section{Appendix}

Appendix 1. BETL system of beliefs as an element of a nested structure: the constructivist context

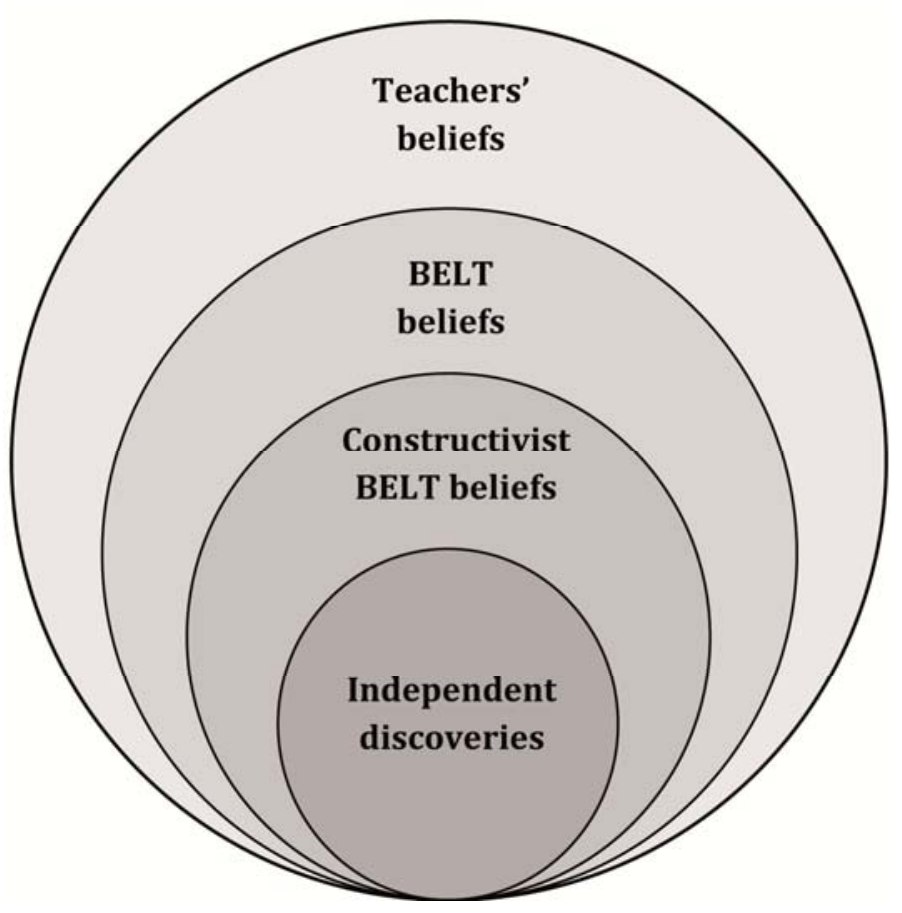

Appendix 2. The process of change of teachers' beliefs

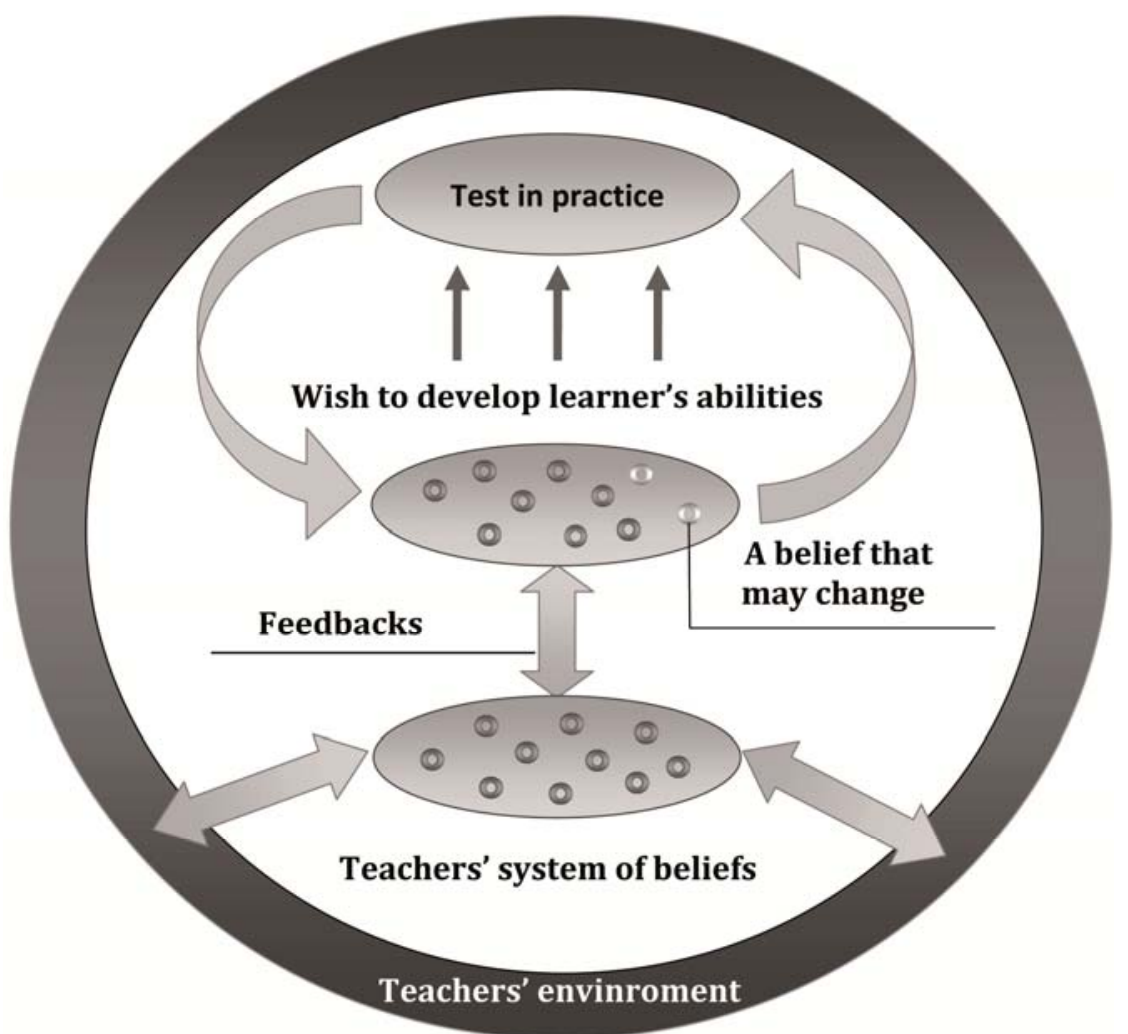




\section{Macrothink}

Appendix 3. SMTBP external environment: ecological system theory approach

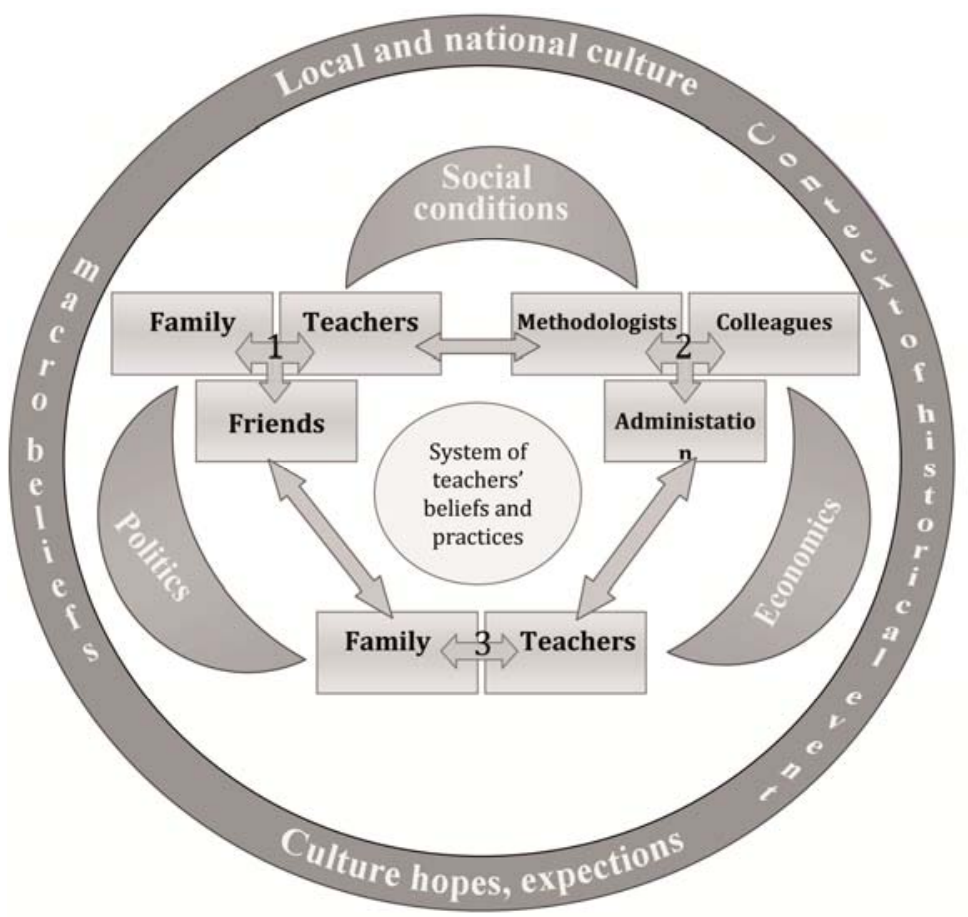

Appendix 4. Cycle of SMTBP changes

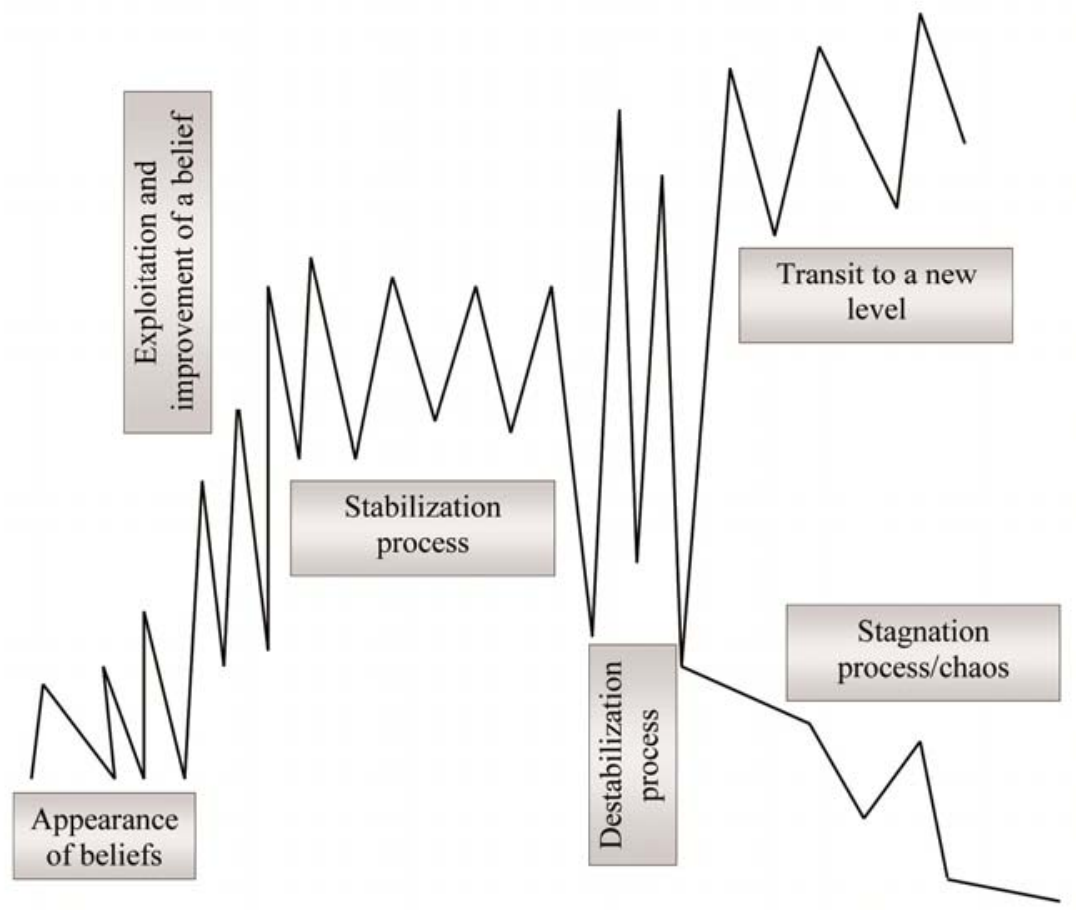

